\title{
Anaphoric R-Expressions as Bound Variables ${ }^{1}$
}

\author{
FELICIA LEE
}

University of British Columbia

\section{The Problem}

San Lucas Quiaviní Zapotec (SLQZ), an Otomanguean language of southern Mexico, regularly allows apparent Principle $\mathrm{B}$ and $\mathrm{C}$ violations. ${ }^{2} \mathrm{R}$-expressions may bind identical R-expressions (1-2) and pronouns may locally bind identical pronouns (3):

(1) R-yu'lààa'z Gye'eihlly Gye'eihlly hab-like Mike Mike "Mike likes himself."

(2) R-cààa'z bxuuhahz ch-iia bxuuhahz hab-want priest irr-go priest "The priest wants to go."

(3) R-yu'lààa'z-ëng la'anng hab-like-3s.prox 3s.prox "He/she likes himself/herself."

Thai also allows apparent Principle C violations:

(4) John koonnuat John

John shaved John

"John shaved himself." [Thai]

\footnotetext{
' I am grateful to Rodrigo Garcia and Sugunya Ruangjaroon for providing the SLQZ and Thai data and judgments in this paper. I am also grateful to Irene Heim, Jim Huang, Pamela Munro, Tim Stowell, and audiences at UBC, University of Canterbury, and NELS 32 for their suggestions and questions on earlier stages of this project. Any remaining errors are my own.

${ }^{2}$ This pattern was described in detail in Munro 1994. Some of the grammaticality judgments reported in this earlier work differ from those found here.
} 


$$
\begin{aligned}
& \text { Aajarn kit waa puak rau chç̧p aajarn } \\
& \text { teacher think that all we like teacher } \\
& \text { "The teacher } r_{i} \text { thinks we like } \text { him }_{\mathrm{i}} \text { " [Thai] }
\end{aligned}
$$

\section{Proposal}

This paper will show that Principles B and C do indeed hold in SLQZ and Thai. I will argue that putatively "bound" R-expressions are not, in fact, true Rexpressions, but bound variables spelled out as copies of their antecedents. Likewise, "locally bound" pronouns are bound copies of their antecedents.

This is consistent with the view that reflexive predicates represent functions mapping a single argument to both argument positions (Reinhart and Reuland 1993):

$$
\lambda \times(P . . x . . . x . .)
$$

Under Reinhart and Reuland's assumptions, reflexivity is realized in one of two ways: either a predicate is lexically specified as reflexive, or it needs to be 'reflexive-marked' by a reflexive morpheme. SLQZ lacks an independent series of reflexive pronouns; thus it uses bound copies to reflexive-mark predicates.

\section{An Earlier Proposal}

The Thai pattern was noted by Lasnik (1986). He concluded that Principle $C$ is subject to parametric variation: Principle $\mathrm{C}$ holds in languages such as English, but not in languages such as Thai. This theory has been invoked to account for the binding facts of Quiegolani Zapotec (related to, but mutually unintelligible from, SLQZ) (Black 1994).

\section{Testing the Hypothesis}

The idea that Principle $C$ is absent in languages such as Thai and SLQZ forces several predictions about the behavior of these languages. The following sections examine these predictions, and show that Principle $\mathrm{C}$ does indeed hold in Thai and SLQZ. Thus, an alternate account must be made for their binding patterns.

\subsection{Prediction 1: All R-expressions Should Be Bindable}

If Principle $C$ did not hold in some languages, then these languages should allow $\mathrm{R}$-expressions to be bound in any context. However, the contexts in which Rexpressions may appear to be bound in Thai and SLQZ are extremely limited.

Lasnik notes that in Thai, R-expressions cannot be bound by pronouns (7) . The same constraint holds in Quiegolani Zapotec (8) (Black 1994) and SLQZ (9):

$$
\begin{aligned}
& \text { *Khaw chççp John } \\
& \text { he likes John } \\
& \text { "He } \text { likes John }_{\mathrm{i}} \text {." [Thai: Lasnik 1986, p. 154] }
\end{aligned}
$$


(9) *B-gwi'ih-ëng lohoh Gye'eihlly perf-look-3s.prox at Mike "He looked at Mike $_{\mathrm{i}}$."

Lasnik attributes this constraint to a referential hierarchy on binding: less referential elements may not bind more referential ones. Thus, R-expressions may be bound by R-expressions, but not by pronouns.

However, constraints on bound R-expressions are stricter than Lasnik suggests. In Thai and SLQZ, R-expressions cannot be bound by different (equally referential) R-expressions (10-11); pronouns can be locally bound neither by R-expressions (12) nor pronouns differing in formality or proximity features (13). The same constraints hold for Thai (14):

R-yu'lààa'z Gye'eihlly me's hab-like Mike teacher "Mike $\mathrm{i}_{\mathrm{i}}$ likes the teacher $\mathrm{j} / \mathrm{i}_{\mathrm{i}}$."

(11) R-yu'lààa'z me's Gye'eihlly hab-like teacher Mike "The teacher likes Mike $_{j * i}$."

(12) R-yu'lààa'z Gye'eihlly la'anng hab-like Mike 3s.prox "Mike likes him/*himself."

(13) R-yu'lààa'z -ih la'anng Hab-like-3s.prox 3s.dist.

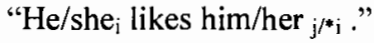

(14) *John koonnuat aajarn John shave teacher "John ${ }_{i}$ shaved the teacher $*_{i} . " \quad$ [Thai]

Thus, apparent binding of R-expressions and local binding of pronouns appear to be subject to the following constraint:

- The Identical Antecedent Requirement: The only R-expressions that can be bound, and pronouns that can be locally bound, are exact copies of their antecedents. 
This requirement calls into question the idea that Principle $\mathrm{C}$ may be freely disobeyed in languages such as Thai and SLQZ.

\title{
3.2. Prediction 2: Thai and SLQZ Should Not Show Crossover Effects
}

If Principle $\mathrm{C}$ were absent in Thai and SLQZ, then wh-traces are predicted to be subject to A-binding, and these languages should not show crossover effects.

Both languages, however, show both strong and weak crossover effects. In (15) and (16), the wh-trace cannot be coindexed with any c-commanding arguments:

Q: Tu r-ralloh la'anng r-yu'lààa'z $(\mathrm{t})$ Li'eb (t)

Who hab-think 3s.prox hab-like Felipe

"Who does he think Felipe likes? /Who does he think likes Felipe?"
A: Lia Paamm-zhi'
Ms. Pam-maybe
"Maybe Pam."

(16)

\author{
* Khray $_{\mathrm{i}}$ thii khaw $_{\mathrm{j}}$ khit $\mathrm{t}_{\mathrm{i}}$ waa Nit rak $\mathrm{t}_{\mathrm{i}}$ \\ who COMP he think COMP Nit love \\ "Who does he $e_{i}$ think Nit loves?" [Thai: Ruangjaroon 2001]
}

Because SLQZ has basic VSO word order and no subject agreement on verbs with non-pronominal subjects, argument wh-questions are often ambiguous between subject and object readings. (This is seen in the two possible interpretations of (15)). (17), however, shows a weak crossover effect: the possessed nominal $x: n n a \dot{a} a n n i$ ', 'his/her mother', can only be interpreted as the object (not the subject) of the sentence:
Tu r-yu'lààa'z $\mathrm{t}$ x:-nnàaan-ni' *t
who hab-like gen-mother-refl.poss
"Who like his/her own mother/*Who does his/her own mother like?"

Thai also shows weak crossover effects. In (18), 'who' must be disjunct from 'his':

(18) MQ khong kao chççp kray

Mother his $s_{i}$ like who;"

"Whoj does his $s_{\mathrm{j}}$ mother like?" [Thai]

These data show that wh-traces cannot be A-bound in Thai and SLQZ, which is unexpected if these languages lacked Principle C. 


\subsection{Prediction 3: Bound DPs Should Be Fully Referential}

If Principle $C$ were absent in Thai and SLQZ, then fully referential DPs should be able to be bound, and should have the same referential force as other Rexpressions.

This, however, proves not to be the case. "Bound" R-expressions in Thai and SLQZ do not receive strict readings in VP deletion contexts, as do typical Rexpressions. Rather, they allow only sloppy (bound variable) readings:

$$
\text { B-gwi'ih Gye'eihlly lohoh Gye'eihlly zë'cy cahgza' Li'eb }
$$
perf-look Mike at Mike likewise Felipe "Mike looked at himself, and Felipe did too."

(*Felipe looked at Mike/ Felipe looked at himself)

(20) John koonnuat khong John lae Peter ko muankan

John shave of John and Peter the same

"John shaved himself, and Peter did too."

(*Peter shaved John/ Peter also shaved himself)

Thus, bound copies in SLQZ and Thai do not have the referential force of normal $\mathrm{R}$-expressions. Rather, they behave like bound variables.

\section{Bound Copies as Bound Variables: The Solution, Revisited}

The presence of Principle $C$ effects and the bound variable readings of apparently bound R-expressions support the proposal that they are not truly referential, but are bound variables spelled out as copies of their antecedents. Likewise, "locally bound" pronouns are also bound copies. This accounts for the general constraint against bound R-expressions and locally bound pronouns, as well as the presence of crossover effects. The copy status of these apparently bound expressions also accounts for the Identical Antecedent Requirement.

\section{Semantic Consequences}

This proposal also predicts another binding constraint in languages such as SLQZ and Thai. If bound copies are bound variables, then they should be, in typetheoretical terms, elements of type $e$. Thus, only DPs of type $e$ should be able to appear as bound copies.

This prediction is borne out. Referential DPs and pronouns, which are elements of type $e$, may appear as bound copies, but quantified phrases, elements of type $\langle<e, t>, t\rangle$, cannot be bound copies $^{3}$ :

$$
\begin{aligned}
& \text { *B-guhty cho'nn ra bxuuhahz cho'nn ra bxuuhahz } \\
& \text { perf-kill three pl. priest three pl. priest } \\
& \text { "Three priests killed themselves." }
\end{aligned}
$$

\footnotetext{
${ }^{3} \mathrm{I}$ assume that in these contexts, both names and definite DPs are elements of type $e$, consistent with Partee's (1986) claim that natural languages allow definite descriptions to be either type $e$ or type $\langle<e, t>, t>$.
} 
(21)

*B-guhty cho'nn ra bxuuhahz cho'nn ra bxuuhahz perf-kill three pl. priest three pl. priest

"Three priests killed themselves."

(22) ??R-a txup tson wnaa r-ka txup tson wnaa gyus

Hab-go two three woman hab-buy two three woman pot

"A few women went to buy a pot."

[Quiegolani Zapotec: Black 1994, p. 103]

(23) *Thuk khon konnuad thuk khon

every one shave every one

"Everyone shaved himself." [Thai]

\subsection{QPs and Bound Copies}

Bound QP copies cannot appear--at least not with a reflexive reading-because they would cause a semantic type clash. Recall that reflexive predicates are assumed to be functions mapping a single argument to both argument positions:

$\lambda x(P . . x \ldots x .$.

Thus, a reflexive predicate such as "kill oneself" is a function that takes an entity to form a second function, which takes the same entity to form a proposition:

$$
\text { [[kill oneself] }]:=\left[\lambda \mathrm{x} \in \mathrm{D}_{\mathrm{e}} \cdot \lambda \mathrm{x} \in \mathrm{D}_{\mathrm{e}} \cdot \mathrm{x} \text { kill } \mathrm{x}\right]
$$

According to this representation, then, bound copies must be of type $e$. Thus, a simple reflexive expression such as (1), gets the representation in (26):

$[[$ Mike likes himself $]]:=\left[\lambda x \in D_{e} \cdot \lambda x \in D_{e} \cdot x\right.$ likes $\left.x\right]($ Mike $)=1$

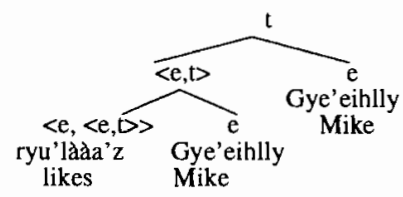

If the reflexive argument is a $\mathrm{QP}$, however, a type clash occurs. Consider the ungrammatical example (21), repeated below:

*B-guhty cho'nn ra bxuuhahz cho'nn ra bxuuhahz perf-kill three pl.priest three pl.priest "Three priests killed themselves."

From (28), we see that the QPs cannot combine compositionally with the predicate, which only selects entities as arguments: 


\section{Anaphoric R-Expressions}

(28)

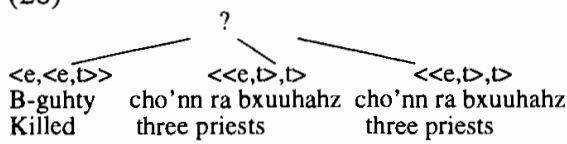

One means of making this structure licit is to type-shift the copies by raising them at LF, leaving traces of type $e$ to combine with the predicate. The following syntactic and semantic structures will result:

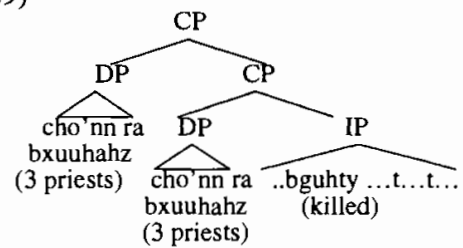

(30)

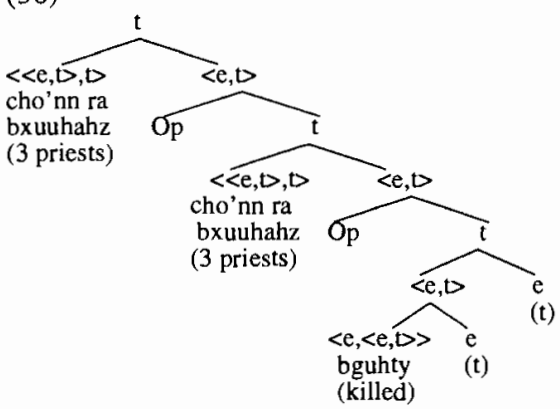

The LF structure in (30), however, does not denote the intended reflexive reading: since each of the traces is bound by a different $\mathrm{QP}$, the sentence can only mean that three priests killed three other priests.

\subsection{Reflexivization of QPs}

SLQZ uses a different pattern to reflexivize QPs: the QP is base-generated as a preverbal topic, and the actual subject of the reflexive predicate is realized as a distal pronoun ${ }^{4}$. The reflexive object is a bound copy of the subject pronoun:
Cho'nn ra bxuuhahz b-guhty-rih
la'arih
Three pl priest perf-kill-3p.dist 3p. dist
"Three priests killed themselves."

\footnotetext{
${ }^{4}$ See Munro (to appear) for the uses of proximate and distal forms in narrative.
} 
Yra'ta' ra bxuuhahz b-guhty-rih la'arih

Every pl priest perf-kill-3p.dist 3p. dist

"Every priest killed himself."

In this construction, reflexive arguments are realized as pronominal variables (thus, elements of type $e$ ), with the QP base-generated in an A' (operator-like) position. (33) shows the semantic representation of (31):

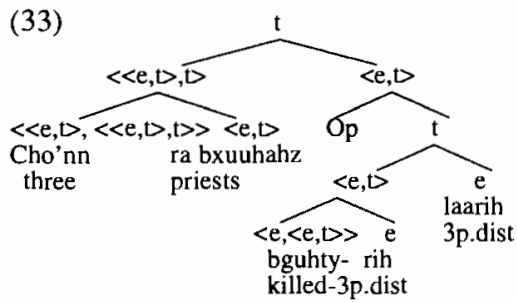

Here, a single QP takes scope over both pronominal, giving a reflexive reading.

To sum up, the failure of quantified arguments to appear as bound copies is due to the bound variable status of bound copies: variables are elements of type $e$, and only elements of type $e$ may appear as bound copies.

\section{SLQZ Bound Copies as Long-Distance Anaphora}

SLQZ also allows non-locally-bound copies, which also behave as bound variables. This section will propose that non-locally-bound copies are longdistance anaphora, and share syntactic and semantic features attested in longdistance anaphora crosslinguistically.

\subsection{Bound Copies as Nominative Anaphors}

Bound copies can be subjects of embedded clauses. (SLQZ has no infinitival clauses; all verbs are marked with tense/aspect markers.) Embedded subject copies are also interpreted as bound variables:

(34) R-cààa'z Gye'eihlly g-ahcnèe Gye'eihlly Lia Paamm zë'cy cahgza' Li'eb hab-want Mike irr-help Mike fem. Pam likewise Felipe "Mike wants to help Pam, and so does Felipe."

(Felipe also wants to help Pam /*Felipe also wants Mike to help Pam)

\subsection{Embedded Object Copies}

Bound copies can also be objects of embedded clauses:

\footnotetext{
${ }^{5}$ Bare nouns in SLQZ may be interpreted as singular or plural, definite or indefinite, depending on context. I will assume that bare nouns are DPs with silent heads, and these DPs are treated as entities.
} 
Object bound copies in embedded clauses can get apparently referential readings:

(36) R-ralloh Gye'eihlly r-yu'l ààa'z-ënn Gye'eihlly Hab-think Mike hab-like-1p Mike

"Mike thinks we likes him $_{\mathrm{i}}$

chiru' zë'cy cahgza' Li'eb

also likewise Felipe

and so does Felipe."

(Felipe thinks we like Mike/Felipe thinks we like him (Felipe))

This, however, is not necessarily evidence against the anaphoric status of the bound copy. Thráinsson (1993) notes that the Icelandic long-distance anaphor sig allows only a sloppy reading in VP-deletion contexts when bound locally, but allows both strict and sloppy readings when its antecedent binds it across a clause:

Jón rakaDi sig og Péter gerDi DaD líka

John shaved self and Peter did so too

(Peter shaved himself (Peter)/ ${ }^{*}$ Peter shaved John)

(38) Jón sagDi [aD Dú hefDir svikiD sig] og Péter gerDi $\mathrm{DaD}$ líka $\mathrm{John}_{\mathrm{i}}$ said that you had betrayed self $\mathrm{f}_{\mathrm{i}}$ and Peter did so too

(Peter said that you betrayed John / Peter ${ }_{i}$ said that you betrayed him ${ }_{i}$ )

This shows that SLQZ bound copies show the same interpretive behavior as local and long-distance anaphors crosslinguistically.

\subsection{Bound Copies in Adjunct Clauses}

Bound copies may also appear in adjunct clauses, where they also get bound variable readings:

Zi'cygàa' nih cay-uhny Gye'eihlly zèèiny b-ii'lly-ga' Gye'eihlly While that prog-do Mike work perf-sing-also Mike "While Mike worked, he sang."

This is unexpected given that no c-command relation holds between the copy and its antecedent. However, the relation between the copy and its antecedent is not unattested: Huang and Tang (1993) note that Chinese long-distance anaphors may appear in adjunct clauses with antecedents in main clauses: 
(40) Ta zhidao [[suiran Lisi piping-le ziji]

He know though Lisi criticise-ASP self

"He ${ }_{i}$ knows that although Lisi $i_{j}$ criticized self $f_{i j}$

dajia haishi hen xihuan ta

all still very like him

we still like him." [Chinese: Huang and Tang 1993, p. 279]

Bound copies in adjunct clauses, like other copies, get bound variable readings and are subject to the Identical Antecedent requirement:

(41) Zi'cygàa' nih cay-uhny Gye'eihlly zèèiny b-ii'lly-ga' Gye'eihlly While that prog-do Mike work perf-sing-also Mike

"While Mike was working, he sang

zë'cy cahgza' Li'eb

likewise Felipe

and so did Felipe."

(*Felipe sang while Mike worked/Felipe sang while he (Felipe) worked)

(42) Zi'cygàa' nih cay-uhny Gye'eihlly zèèiny b-ii'lly-ga'-ng

While that prog-do Mike work perf-sing-also-3s.prox

"While Mike was working, he/she (someone else) sang."

This supports the idea that adjunct bound copies are semantically dependent on their antecedents, and are not merely instances of accidental coreference.

\subsection{Non-Local Copies Are Not Logophors}

It has been claimed that the non-bound anaphora cross-linguistically are logophors: pronominal elements representing one whose speech, thoughts, or perceptions are being reported. An example of this is the use of myself in (43):

As for myself, I like sugar in my coffee.

Long-distance anaphora have also been claimed to be logophors (Reinhart and Reuland 1993, Huang and Liu 2001). Under these accounts, the distribution of long-distance anaphora is constrained primarily by semantic and pragmatic factors, rather than purely structural ones.

However, non-locally bound copies in SLQZ can appear in contexts in which their use is not logophoric. Such contexts are noted by Dubinsky and Hamilton (1998), who argue that epithets can only be c-commanded by their antecedents in anti-logophoric environments: 
${ }^{*}$ Felipe $_{i}$ is afraid his teacher failed the poor guy ${ }_{i}$.

Felipe $_{i}$ ran over the man who tried to help the poor guy .

Example (44) is ungrammatical because the poor guy is c-commanded in a logophoric context: Felipe's feelings are being described. (45), on the other hand, is grammatical because the context in which the epithet appears is antilogophoric: it says nothing about Felipe's state of mind during the action.

If non-locally-bound copies in SLQZ were logophors, they would be ruled out in contexts similar to that in (45). However, this prediction is not borne out: (46) shows that non-locally-bound copies can occur in anti-logophoric contexts:

$$
\begin{aligned}
& \text { B-tàa'az Gye'eihlly bèe'cw nih b-da'uhgya'ah Gye'eihlly } \\
& \text { perf-hit Mike dog REL perf- bite Mike } \\
& \text { "Mike hit the dog that bit him." }
\end{aligned}
$$

Here, the copy is licit even though (46), like (45), does not describe the perspective of the subject or its copy. Hence, it cannot be the case that bound copies are logophors.

\section{Conclusion}

This paper has shown that the apparently bound R-expressions and locally bound pronouns that appear in SLQZ and Thai do not represent Principles B or C violations. Rather, these elements are semantically and syntactically bound variables that are spelled out as copies of their antecedents. In SLQZ, which lacks a morphologically distinct series of anaphors, bound copies serve as both local and long-distance anaphora.

\section{References}

Black, Cheryl. 1994. Quiegolani Zapotec Syntax. PhD dissertation, UC-Santa Cruz.

Dubinsky, Stanley \& R. Hamilton. 1998. Epithets as Antilogophoric Pronouns. Linguistic Inquiry 29.4: 685-673.

Hornstein, Norbert. 2001. Move! A Minimalist Theory of Construal. Oxford: Blackwell.

Huang, C.T. James. 1982. Logical Relations in Chinese and the Theory of Grammar. PhD dissertation, MIT.

Huang, C.T. James \& C.-S. Luther Liu. 2001. Logophoricity, Attitudes, and Ziji at the Interface. In P. Cole et al (eds.) Long-Distance Reflexives, Syntax and Semantics. San Diego: Academic Press. 
Huang , C.T. James \& C.-C. Jane Tang. 1993. The Local Nature of Long-Distance Anaphora in Chinese. In J. Koster \& E. Reuland (eds.) Long Distance Anaphora. Cambridge: Cambridge University Press.

Koopman, Hilda \& D. Sportiche. 1989. Pronouns, Logical Variables, and Logophoricity in Abe. Linguistic Inquiry 20.4: 555-888.

Lasnik, Howard. 1991. On the Necessity of Binding Conditions. In R. Frieden, (ed.) Principles and Parameters in Comparative Grammar. Cambridge: MIT Press.

Lee, Felicia. 1998. Evidence for Tense in a 'Tenseless' Language. Proceedings of NELS 29.

Lee, Felicia. 1999. Antisymmetry and the Syntax of San Lucas Quiavini Zapotec. PhD dissertation, UCLA.

Munro, Pamela. 1994. Coreference Phenomena in San Lucas Quiaviní Zapotec. Ms., UCLA.

Munro, Pamela. To appear. Hierarchical Pronouns in Discourse: Third-Person Pronouns in San Lucas Quiaviní Zapotec Narratives. SWJL.

Munro, Pamela \& F.H. Lopez (with R. Garcia and O. V. Méndez). 1999. Dicyonaary X:te:e'n Di:i'zh Sah Sann Luu'c: San Lucas Quiavini Zapotec Dictionary. Diccionario Zapoteco de San Lucas Quiaviní. Los Angeles: UCLA Chicano Studies Research Center Publications.

Partee, Barbara. 1986. Noun Phrase Interpretation and Type-Shifting Principles. In Jeroen Groenendijk et al (eds.) Studies in Discourse Representation Theory and the Theory of Generalized Quantifiers. Dordrecht: Foris.

Reinhart, Tanya \& E. Reuland. 1993. Anaphors and Logophors: An Argument Structure Perspective. In J. Koster \& E. Reuland (eds.) Long Distance Anaphora. Cambridge: Cambridge University Press.

Ruangjaroon, Sugunya. 2001. Thai Wh-Movement as Focus. Ms., UBC.

Thráinsson, Höskuldur. 1993. Long-Distance Reflexives and the Typology of NPs. In J. Koster \& E. Reuland (eds.) Long Distance Anaphora. Cambridge: Cambridge University Press.

Department of Linguistics

University of British Columbia

E270-1866 Main Mall

Vancouver, B.C. V6T 1Z1 Canada

leefa@interchange.ubc.ca 